\section{Arantes ACQ. Histórias lindas de morrer. Rio de Janeiro: Sextante; 2020.}

\author{
Juliana Alvares Duarte Bonini Campos \\ (https://orcid.org/0000-0001-7123-5585) ${ }^{1}$ \\ ${ }^{1}$ Faculdade de Ciências Farmacêuticas, Universidade \\ Estadual Paulista. São Paulo SP Brasil.
}

O título do livro por si só já seria motivo suficiente para despertar nosso interesse. Uma escolha delicada e assertiva. A autora transforma uma expressão coloquial, um "modo de falar" tão comum, em algo profundo, trazendo beleza, suavidade e individualidade à narrativa de histórias do final da vida de alguns de seus pacientes. As histórias são contadas a partir do olhar da autora, médica de cuidados paliativos, que nos presenteia com histórias de 14 de seus pacientes e do final da vida de seus pais. Assim, como em seu livro anterior, A morte é um dia que vale a pena viver ${ }^{1}$, essa obra é composta por capítulos breves, com linguagem digestiva e com um olhar sensível em relação ao cuidado e aos direitos dos indivíduos que sabem que estão próximos ao dia de sua morte. Contudo, agora, desvela-se também a profundidade do aprendizado que cada uma das histórias apresentadas carrega para a vida de todos, equipe médica, cuidadores e familiares o que transborda para os leitores.

Durante o texto, a autora define e diferencia ortotanásia, eutanásia, suicídio assistido e kalotanásia. Esse último trata de termo pouco conhecido entre o senso comum e até mesmo entre profissionais da saúde merecendo aqui, portanto, a exposição da definição que Arantes nos apresenta: "é a morte que faz sentido na história de cada pessoa, individualmente", e durante o texto fica claro que o papel dos cuidados paliativos é reconhecer que a morte acontece, é "trabalhar a favor da vida até que a morte chegue" transformando essa caminhada numa experiência afetiva, significativa e sem sofrimento utilizando-se, portanto, da ortotanásia (morte correta) buscando a kalotanásia (morte bela). Para Floriani² ${ }^{2}$ a kalotanásia representa ainda um tipo específico de luta onde mesmo sabendo que vai morrer o indivíduo trava uma luta em instâncias mais profundas de sua natureza o que lhe dá um sentido e disposição de enfrentamento, transcendendo a morte. Essa postura, constitui-se em substrato que organiza e dissemina um conjunto de ações transformadoras de cuidados que pretende reviver um processo de morrer transformador agregando aspectos culturais e estéticos à morte correta $^{2,3}$. Ainda, é realizada a recomendação de que os cuidados paliativos devam ser tomados logo após o diagnóstico de uma enfermidade grave oferecendo ao paciente a oportunidade de acolhimento e auto- nomia em relação ao rumo de sua caminhada e a seu desfecho transformando a caminhada ao fim da vida em algo nobre, digno e significativo ${ }^{4}$. Silva et al. ${ }^{5}$ alertam que apesar de, atualmente, os profissionais conhecerem os diferentes conceitos de terminalidade e reconhecerem sua importância, em seu estudo, observaram que na prática os princípios que envolvem esses conceitos não estiveram efetivamente presentes, o que pode influenciar negativamente assistência. Assim, destaca-se a importância de realização de treinamento dos profissionais de saúde e do trabalho de uma equipe interdisciplinar para colocar em prática não apenas a aceitação da morte no tempo certo, mas também a adoção de medidas de cuidado para aliviar o sofrimento do indivíduo e de sua família 5 .

Durante as narrativas apresentadas por Arantes percebe-se o grande envolvimento da autora com cada uma das histórias contadas, uma proximidade legítima, carregada de afeto, respeito, humildade e acima de tudo de reconhecimento da fragilidade e da importância do outro. Nessa breve descrição da obra não revelarei o conteúdo dessas narrativas, pois, cada uma delas nos remete a uma experiência particular que merece ser vivida na íntegra por cada leitor.

No transcorrer do texto também podem ser encontrados elementos para reflexão em relação à formação médica e à atuação dos profissionais da saúde. Arantes aponta, em alguns casos específicos da narrativa, para a falta de congruência entre o aprendizado acadêmico e a prática clínica além de destacar o excesso de fragmentação (especialização) da medicina que "tenta encaixar todo problema do paciente dentro do que sabem tratar e não dentro do que a doença realmente traz". Entretanto, o que mais chama atenção é seu apelo para a humanização dos profissionais envolvidos no cuidado de pessoas que se aproximam do fim da vida. É interessante que Muccioli et al. ${ }^{6}$ nos traz um breve editorial com questões relativas a esse tema propondo uma reflexão sobre a humanização ou re-humanização da medicina. Os autores afirmam que a medicina seguiu um rumo mais técnico deixando de lado, ou em segundo plano, o lado humanístico. Os autores questionam "onde foi parar a relação médico-paciente", o diálogo e a proximidade e propõem a todos coragem para rever e mudar, para resgatar o valor da medicina que segundo os autores trata de ver o paciente como um ser humano único e respeitá-lo como tal, para poder entendê-lo e tratá-lo. Essa preocupação com a "re -humanização" dos profissionais de saúde é tema recorrente na literatura, a necessidade de resgatar um cuidado humanizado é consensual e as estraté-

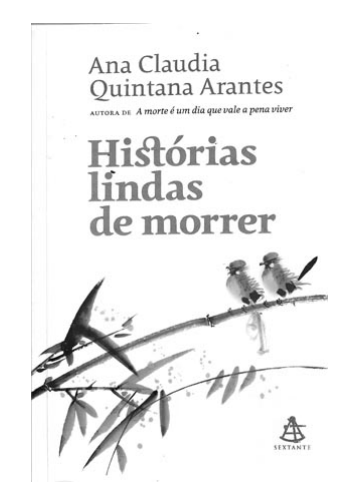


gias para que isso possa ser realizada são diversas como a proposição da humanização enquanto política pública, revisão do processo de formação das escolas médicas desde a graduação, avaliação dos protocolos de cuidado na rotina médica, avaliação da macro e micro gestão dos sistemas de saúde ${ }^{7-9}$. Nesse sentido, o livro de Arantes é capaz de trazer à tona esse tipo de preocupação e reflexão o que propicia um movimento salutar posto a cada leitor buscando um olhar mais profundo da vulnerabilidade do outro e do sistema de cuidado à saúde.

Na última parte do livro a autora expõe 12 características, definidas por um grupo britânico de estudo sobre envelhecimento, que estão envolvidas com a "morte bela" ou "boa morte" acrescentando a importância da consciência da morte pelo paciente, o respeito a seus desejos e os ajustes sociais. A obra termina com os Agradecimentos da autora que também não nos passam desapercebidos, tamanha sua humildade, pois são edificados numa profunda gratidão a todos que a "honraram por ser parte da vida deles". Ao final da leitura, tem-se a sensação de conhecer um pouco da vivência de diferentes pessoas rumo ao fim da vida e fica evidente nesse percurso a filosofia de trabalho da autora e sua equipe interdisciplinar que buscam incessantemente o acolhimento dos pacientes e de seus familiares para que os mesmos possam desfrutar de uma caminhada rumo ao fim da vida olhando nos olhos de quem as cuida e percebendo o acolhimento nesse olhar.

Assim como seu livro anterior, recomendo sua leitura a todos, pessoas comuns, doentes, fa- miliares, educadores e profissionais de saúde em geral não apenas médicos. Certamente, conhecer cada uma das narrativas apresentadas representará ao leitor uma oportunidade de pensar e de ressignificar a morte abrindo espaço para transformação, para o cuidado e para um caminhar mais leve e acolhedor rumo ao final da vida pois, "a vida que se impõe, só acaba quando termina".

\section{Referências}

1. Arantes ACQ. A morte é um dia que vale a pena viver. Alfragide: Oficina do Livro; 2019.

2. Floriani CA. Moderno movimento hospice: kalotanásia e o revivalismo estético da boa morte. Rev Bioet 2013; 21(3):397-404.

3. José PC. O 'testamento vital': direitos do paciente e os cuidados paliativos. Front Interdiscipl Direito 2019; 1(1):138-151.

4. Kovács MJ. A caminho da morte com dignidade no século XXI. Rev Bioet 2014; 22(1):94-104.

5. Silva RS, Evangelista CLS, Santos RD, Paixão GPN, Marinho CLA, Lira GG. Percepção de enfermeiras intensivistas de hospital regional sobre distanásia, eutanásia e ortotanásia. Rev Bioet 2016; 24(3):579-589.

6. Muccioli C, Campos MSQ, Dantas PEC, Goldchmit M, Bechara SJ, Costa VP, Matayoshi S. A humanização da Medicina. Arq Bras Oftalmol 2007; 70(6):897.

7. Goulart BNG, Chiari BM. Humanização das práticas do profissional de saúde - contribuições para reflexão. Cien Saude Colet 2010; 15(1):255-268.

8. Franco HCP, Stigar R, Souza SJP, Burci LM. Papel da enfermagem na equipe de cuidados paliativos: a humanização no processo da morte e morrer. Rev Gestão Saúde 2017; 17(2):48-61.

9. Caprara A, Franco ALS. A relação paciente-médico: para uma humanização da prática médica. Cad Saude Publica 1999; 15(3):647-654. 